\title{
Assembly Mechanism and the Morphological Analysis of the Robust Superhydrophobic Surface
}

\author{
Doeun Kim ${ }^{1,2}$, Arun Sasidharanpillai ${ }^{1,2} \mathbb{E}$, Ki Hoon Yun ${ }^{1,3}$, Younki Lee ${ }^{2} \mathbb{D}$, Dong-Jin Yun ${ }^{4}$, \\ Woon Ik Park ${ }^{1}$, Jiwon Bang ${ }^{1}(1)$ and Seunghyup Lee ${ }^{1, *(1)}$ \\ 1 Electronic Convergence Materials Division, Korea Institute of Ceramic Engineering and Technology, Jinju, \\ Gyeongnam 52851, Korea \\ 2 Department of Materials Engineering and Convergence Technology, Gyeongsang National University, Jinju, \\ Gyeongnam 52828, Korea \\ 3 Department of Convergence engineering, Pusan National University, Busan 46241, Korea \\ 4 Analytical Engineering Group, Samsung Advanced Institute of Technology, Suwon 440-600, Korea \\ * Correspondence: shbelly@kicet.re.kr; Tel.: +82-55-792-2678
}

Received: 21 June 2019; Accepted: 24 July 2019; Published: 26 July 2019

check for updates

\begin{abstract}
Robust superhydrophobic surfaces are fabricated on different substrates by a scalable spray coating process. The developed superhydrophobic surface consists of thin layers of surface functionalized silica nanoparticle $\left(\mathrm{SiO}_{2}\right)$ bound to the substrate by acrylate-polyurethane (PU) binder. The influence of the $\mathrm{SiO}_{2} / \mathrm{PU}$ ratio on the superhydrophobicity, and the robustness of the developed surface, is systematically analyzed. The optimized $\mathrm{SiO}_{2} / \mathrm{PU}$ ratio for prepared superhydrophobic surfaces is obtained between 0.9 and 1.2. The mechanism which yields superhydrophobicity to the surface is deduced for the first time with the help of scanning electron microscopy and profilometer. The effect of mechanical abrasion on the surface roughness and superhydrophobicity are analyzed by using profilometer and contact angle measurement, respectively. Finally, it is concluded that the binder plays a key role in controlling the surface roughness and superhydrophobicity through the capillary mechanism. Additionally, the reason for the reduction in performance is also discussed with respect to the morphology variation.
\end{abstract}

Keywords: robust superhydrophobic surface; surface assembly mechanism; surface disintegration mechanism

\section{Introduction}

Recently, studies regarding biomimetic have been actively carried out as attempts to advance material technology. Super-strong fibers mimicking spider fibers and anti-reflective displays mimicking moth eyes are representative examples. Among them, smart surfaces, which mimic the self-cleaning ability of the lotus, have attracted scientific attention for the past few decades [1-3]. It is generally accepted that superhydrophobic surfaces—contact angle $>150^{\circ}$ and hysteresis $<10^{\circ}$-are able to bounce off water droplets without wetting its surface [4-7]. Efforts to mimic natural superhydrophobicity has lead researchers to fabricate artificial superhydrophobic surfaces which can be applied for a variety of applications, including self-cleaning window and panels, anti-icing, water-resistant fabrics, anti-fouling, drag reduction, corrosion resistance, etc., [8-12]. These properties are used to provide waterproof properties to electronic devices [10], or to provide self-cleaning and anti-fouling functions that remove dirt, viruses, and bacteria from medical apparatuses [13].

The essential requirements for a surface to be superhydrophobic is that it should have low surface energy and complex nano-scale surface morphology as suggested by the Cassie-Baxter model [14-18]. Studies have demonstrated that solid surface with increased surface roughness can 
enhance superhydrophobicity $[6,19]$. The rough structure can trap air inside, and pushes off the water droplets which comes in contact with the surface. The underlying mechanism is based on the extreme reduction in contact surface area due to the nanostructure, which helps easy sliding of water droplets $[20,21]$. Thus, it is necessary to tailor a rough structure for achieving superhydrophobicity.

In order to control surface roughness, several methods have been adopted, including the sol-gel process, chemical etching, layer-by-layer assembly, electrostatic spinning, chemical vapor deposition, and lithographic process [2,17-23] However, these methods have issues, such as vulnerable mechanical strength, process complexity, high investment costs, limited substrate selection, and difficulty in mass production. These issues have been raised, but in particular, poor durability in mechanical strength have been emphasized. Remarkable methods have been proposed for enhancing the mechanical properties of superhydrophobic surfaces [24]. One of these methods is the protection of fragile fine-scale surface topographies against mechanical wear by assembling larger scale sacrificial micro-pillars on the polymer surfaces. When the micro-scale structures are built upon surfaces with nano-level roughness, the durability of compression could be improved up to $120 \mathrm{kPa}$ [25]. However, the production process for such structures is complicated, as the self-cleaning function is affected by the ratio and patterns of the hierarchical structures. Meanwhile, studies using the pyramid structure have indicated that superhydrophobicity is retained after mechanical abrasion. When mechanically worn, the nano-roughness is ensured by sacrificing the tips of pyramids [26]. However, the surface is vulnerable under large and continuous stress. To date, the demand for the robustness of the superhydrophobic surface has not subsided. Recently, a smart approach to increase mechanical durability has been proposed by applying superhydrophobic paint on commercial adhesives to implement properties on various substrates, and to promote robustness $[27,28]$. This is a simple and flexible method that can be used for mass-production. Even though there are plenty of reports about spray-coating of superhydrophobic surfaces on various substrates [29-31], the study lacks knowledge about the assembly mechanism in the early stage of surface formation. In this work, we synthesized superhydrophobic surfaces by spray coating surface treated $\mathrm{SiO}_{2}$ agglomerates on dissolved polyurethane (PU) (binder) which are deposited on various substrates. In order to investigate the assembly mechanism, the morphology of the superhydrophobic surfaces was controlled systematically by adjusting the weight ratio of the sprayed particles and the binder. The prepared samples were mechanically abraded by using a rubbing machine. The surface with optimal $\mathrm{SiO}_{2} / \mathrm{PU}$ ratio presented robustness that maintained its superhydrophobicity after many cycles of mechanical abrasion. The assembly mechanism responsible for superhydrophobicity in these coatings were studied with the help of scanning electron microscopy and roughness analysis. Furthermore, the degradation in superhydrophobicity (as a result of the collapse of the micro-protuberances) is due to the applied stress is also discussed through roughness analysis. The underlying phenomenon for the formation of the superhydrophobic surface is the creation of two-length scale rough surface on the spray-coated substrate. All of the previous studies analyzed only the effect of particle/polymer ratio on the creation of such surfaces, could not shed light into the mechanism of how these micro/nano roughness are created on the surface of dissolved binder. In this article we report the experimental evidence of binder penetration through the porous $\mathrm{SiO}_{2}$ agglomerates, and through capillary mechanism, which is responsible for the formation of a robust rough surface. The systematic investigation on the assembly mechanism and the behavior of the sprayed $\mathrm{SiO}_{2}$ particles presented here will help industrialists to develop mechanically durable superhydrophobic surfaces.

\section{Materials and Methods}

\subsection{Preparation of Hydrophobic Solution}

A superhydrophobic solution was prepared through different steps. Initially, $2 \mathrm{~g}$ of $\mathrm{SiO}_{2}$ powder (5-15 nm, Sigma Aldrich, Saint Louis, MO, USA) and $40 \mathrm{~mL}$ of absolute ethanol were mixed in a beaker. Since $\mathrm{SiO}_{2}$ is hydrophilic in nature, surface treatment should be done to make it hydrophobic. 
It was done by adding $2 \mathrm{~mL}$ of Octadecyltrimethoxysilane (OTS, 90\%, Sigma Aldrich) into the stirring solution, and the stirring was continued for $2 \mathrm{~h}$. The mixed solution was then poured on to a glass dish and allowed to dry at room temperature for $8 \mathrm{~h}$. The superhydrophobic solution was obtained by dispersing the dried powder in $100 \mathrm{~mL}$ of absolute ethanol for $3 \mathrm{~h}$.

\subsection{Preparation of Superhydrophobic Coating}

Glass slide, aluminum sheet, alumina plate, and artificial fibers were used as the substrate for fabricating superhydrophobic surfaces. For cleaning, all substrates were ultra-sonicated successively for $10 \mathrm{~min}$ in ethanol and distilled water, then dried with nitrogen gas. The acrylic polyurethane (PU) resin and curing agent (HS Clear, KCC, Seoul, Korea) prepared in a ratio of 2:1 was stirred manually. The substrate was then spin-coated at 200 RPM with the dissolved PU for $30 \mathrm{~s}$. Immediately, the hydrophobic solution was spray-coated on the surface of the PU coated substrate. In addition, each surface was constructed by systematically adjusting the amount of spray of the superhydrophobic solution. The sample was then cured for $30 \mathrm{~min}$ in a hot air oven. The weight of the binder and the sprayed particles was measured after drying completely.

\subsection{Characterization}

For particle size analysis, the solution was diluted in ethanol and evaluated by measuring contact angle using laser scattering particle size distribution analyzer (LA-950V2, HORIBA, Kyoto, Japan). Superhydrophobicity of the spray-coated substrates were confirmed by contact angle analyzer (Phoenix-10, SEO, Kromtek Sdn Bhd, Shah Alam, Malaysia). The advancing and receding angles of the water droplets on each surface were measured, and the hysteresis was calculated. The surface morphology of each sample was characterized by SEM (SM-300, TOPCON, Tokyo, Japan). Furthermore, the surface roughness measurement of each sample was carried out by Surface Profilometer (Dektak, VEECO, Plainview, NY, USA). For the evaluation of the mechanical durability of superhydrophobic surfaces, the abrasion rubbing machine (KP-M4250, KIPAE, Gyeongju, Korea) was used. The coated substrates under test were fixed on a leveling plate and loaded with a regulated load using a home-made device. We controlled the pressure on coated substrates and measured the changes in contact angle after the abrasion. Ultimately, the durability of the coated surface was identified.

\section{Results and Discussion}

The fabrication process for hierarchical superhydrophobic surfaces was schematically shown in Figure 1. [32,33]. Particle size analysis of the surface treated and dried $\mathrm{SiO}_{2}$ agglomerates are shown in Figure 1a. In order to make $\mathrm{SiO}_{2}$ hydrophobic, the agglomerated powder should be surface functionalized with some suitable agent. Sriramulu et al. has investigated the mechanism of functionalization of silane coupling agent, such as OTS on $\mathrm{SiO}_{2}$ nanoparticles, for application in superhydrophobic surfaces. They demonstrated that surface functionalization of silica nanoparticle reduces the adsorption of water [34]. The alkylalkoxysilanes like OTS can replace the alkoxy group with $-\mathrm{OH}$ in the polar solvent. It requires hydroxylated surface as a substrate for their association. The silanes on the surface of $\mathrm{SiO}_{2}$ replaced with $-\mathrm{OH}$ is adsorbed on the substrate, and then they form $\mathrm{Si}-\mathrm{O}-\mathrm{Si}$ bonds through dehydration and polymerization $[35,36]$. Through the reaction with OTS, the surface energy of the $\mathrm{SiO}_{2}$ reduced and hydrophobicity is increased [7]. These surface functionalized $\mathrm{SiO}_{2}$ agglomerates are sprayed onto the dispersed binder film on the substrate and then cured at $60^{\circ} \mathrm{C}$ for $30 \mathrm{~min}$. Applying this technique, the surfaces were fabricated by controlling roughness and hydrophobicity on various substrates. 


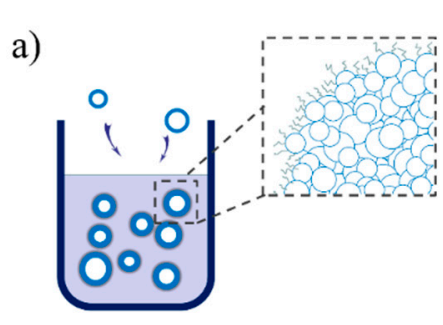

Surface Reaction

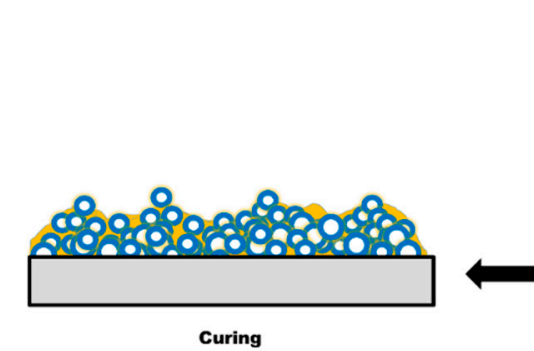

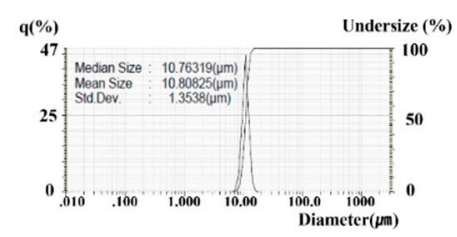

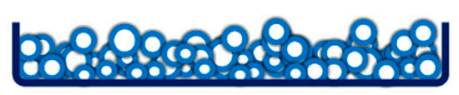

Dry and Collect
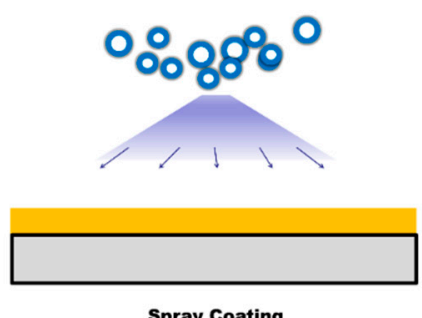

Spray Coating
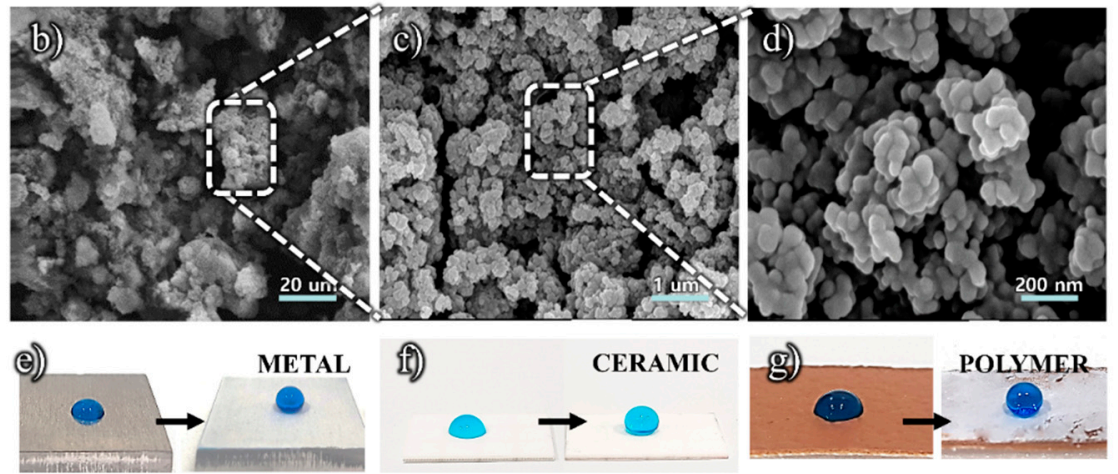

Figure 1. (a) Schematic for the evolution of rough surface using the spray-coating technique, (b-d) Surface morphology of the superhydrophobic surface structure at different magnifications, (e-g) Digital images of water droplets on the various superhydrophobic surfaces.

Figure $1 \mathrm{~b}-\mathrm{d}$ shows the surface morphologies of the superhydrophobic surface at different magnifications. It is clear from the figure that fine nanoparticles are clustered to form a surface with higher roughness, which is considered as one of the essential requirements for superhydrophobicity. Additionally, the observed porosity inside the structure can trap air and thereby reduce the contact area of water drops with the surface, which is critical for enhancing superhydrophobicity. In short, superhydrophobicity could be achieved by using hierarchical arrangements of micro/nano-sized structure. Ironically, poor dispersion of $\mathrm{SiO}_{2}$ nanoparticle is preferably effective in making such a rough hierarchical surface. The proposed technique for making superhydrophobic surface has greater advantages over conventional methods-in this case, there is a wider possibility of application of any type of solid substrate. It is believed that superhydrophobicity is only affected by the assembly of the binder and surface modified particles. For example, on a variety of substrates made of materials, such as metal, ceramic, and polymers, superhydrophobicity was successfully obtained, and is shown in Figure 1e-g. There is no shape change observed for ceramic substrates, due to its inherent rigidity and stiffness. This method is applicable to any substrate to which the binder has good adhesion. In our work, we used acrylate-containing PU as a binder, which has many advantages, including good mechanical properties, low-temperature curability, solvent resistance, etc., [37,38].

We systematically investigated the influence of filler and binder on the roughness of the coated substrates by controlling the powder to binder weight ratio. Figure 2a-d shows the SEM image and roughness profile of the spray-coated substrates with different $\mathrm{SiO}_{2} / \mathrm{PU}$ ratio (denoted as $\mathrm{R} \_0.03, \mathrm{R} \_0.15$, R_0.3, R_0.9). The weight of the PU coating was measured in an indirect way-by subtracting the 
weight of the substrate before coating from that of the substrate after coating. The same procedure was adopted for measuring the weight of the $\mathrm{SiO}_{2}$ nanopowder. It should be noted that all the weights were taken on dried samples. After analyzing the SEM images (Figure 2a), it is clear that the low $\mathrm{SiO}_{2} / \mathrm{PU}$ weight ratio (R_0.03) is not enough to achieve a high roughness for getting superhydrophobicity. The measured roughness for $R_{-} 0.03$ is $0.116 \mu \mathrm{m}$, the corresponding contact angle is $74.7^{\circ}$, which is well below the par level to achieve superhydrophobicity. Also, the particles are seen almost immersed in the binder matrix, as a result of the action of binder to minimize its surface energy [19,39]. Moving on to Figure $2 b$, the increased weight ratio (R_0.15) has improved the surface roughness to a much higher value of $3.921 \mu \mathrm{m}$, still, the contact angle is very low $\left(90.8^{\circ}\right)$ to provide superhydrophobicity. Increasing weight ratio to higher values, for example, to 0.3 and 0.9 , could enhance the surface roughness to $13.165 \mu \mathrm{m}$ for R_0.3 and $15.517 \mu \mathrm{m}$ for R_0.9, respectively. Corresponding contact angles are $148.2^{\circ}$ and $158^{\circ}$, which clearly indicates that the surface is superhydrophobic. In Figure $2 \mathrm{~d}$, a large scale-roughness with $15.517 \mu \mathrm{m}$ was detected, but the change of the contact angle and $R_{\mathrm{a}}$ was reduced. The stage of $\mathrm{R} \_0.3$ and R_0.9 show the surface completely covered by particles. Thus, the surface roughness increases by the number of the sprayed particle, but tends to be no longer increased above a certain level.

Particle weight ratio

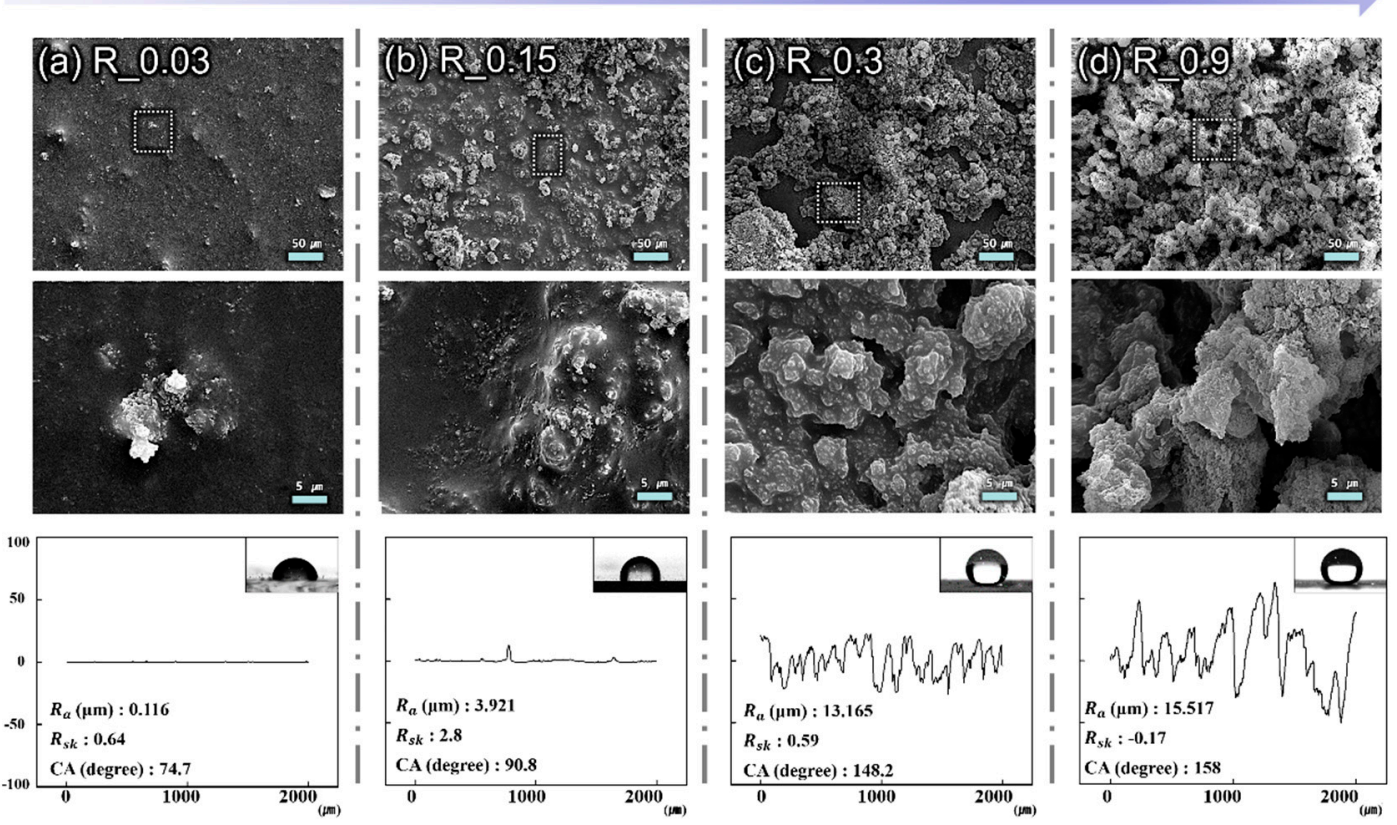

Figure 2. SEM images, roughness profiles and contact angle images of the surface with different weight ratios of the particles to the binder of (a) $R_{-} 0.03,(\mathbf{b}) \mathrm{R} \_0.15$, (c) $\mathrm{R} \_0.3$, and (d) R_0.9.

The schematics for the $\mathrm{SiO}_{2}$ nanoparticle assembly mechanism on PU are shown in Figure 3. When agglomerated $\mathrm{SiO}_{2}$ nanoparticles sprayed on to the surface of the binder, the binder ascends and holds the nanoparticles. As explained earlier, this occurs as a result of the action of binder to minimize surface energy $[40,41]$. Meanwhile, to minimize the surface energy, it is confirmed that the PU covers the particles (SEM image of Figure 2a). Creation of multimodal texture, is essential for fabrication of superhydrophobic surface with particles having lower hydrophobicity, can be done either by aggregation of particles directly on the substrate or by deposition of dispersed aggregates. Conventionally, these dispersions are directly coated on the substrate. Thus, the peculiarities of the formed structures are the result of the interplay between various forces, such as van der Waals interactions, depletion interaction, ion-electrostatic repulsion and ultimately the image-charge forces and the structural forces, particularly its polarity and magnitude determine the properties of the final system. Since superhydrophobicity is a surface feature, which depends only on the nature of a few 
monolayers on the surface, we have the freedom to choose any material which can strongly bond the surface layer with the substrate [32]. In our experiment, we used strongly adhering polyurethane coating on the substrates and sprayed the highly agglomerated and surface functionalized $\mathrm{SiO}_{2}$ nanoparticles (Agglomerated average particle size $=10 \mu \mathrm{m}$ ) dispersed in ethanol (Figure 1). There is a sharp rise in the binder level above its mean surface, as shown in the cross-sectional SEM image in Figure 3, which let us attribute capillary action of the pre-coated binder as the responsible mechanism for creating such a rough surface with plenty of micro-protuberances. Because of the fine space between the sprayed particles, the binder can effectively infiltrate and surround. Due to the surface tension of the penetrated binder, it was dragged up to the top of the $\mathrm{SiO}_{2}$ agglomerates. This continuous process would finally yield a rough surface with plenty of hills and valleys, which can trap air inside, and, thus, forms a perfect superhydrophobic surface.

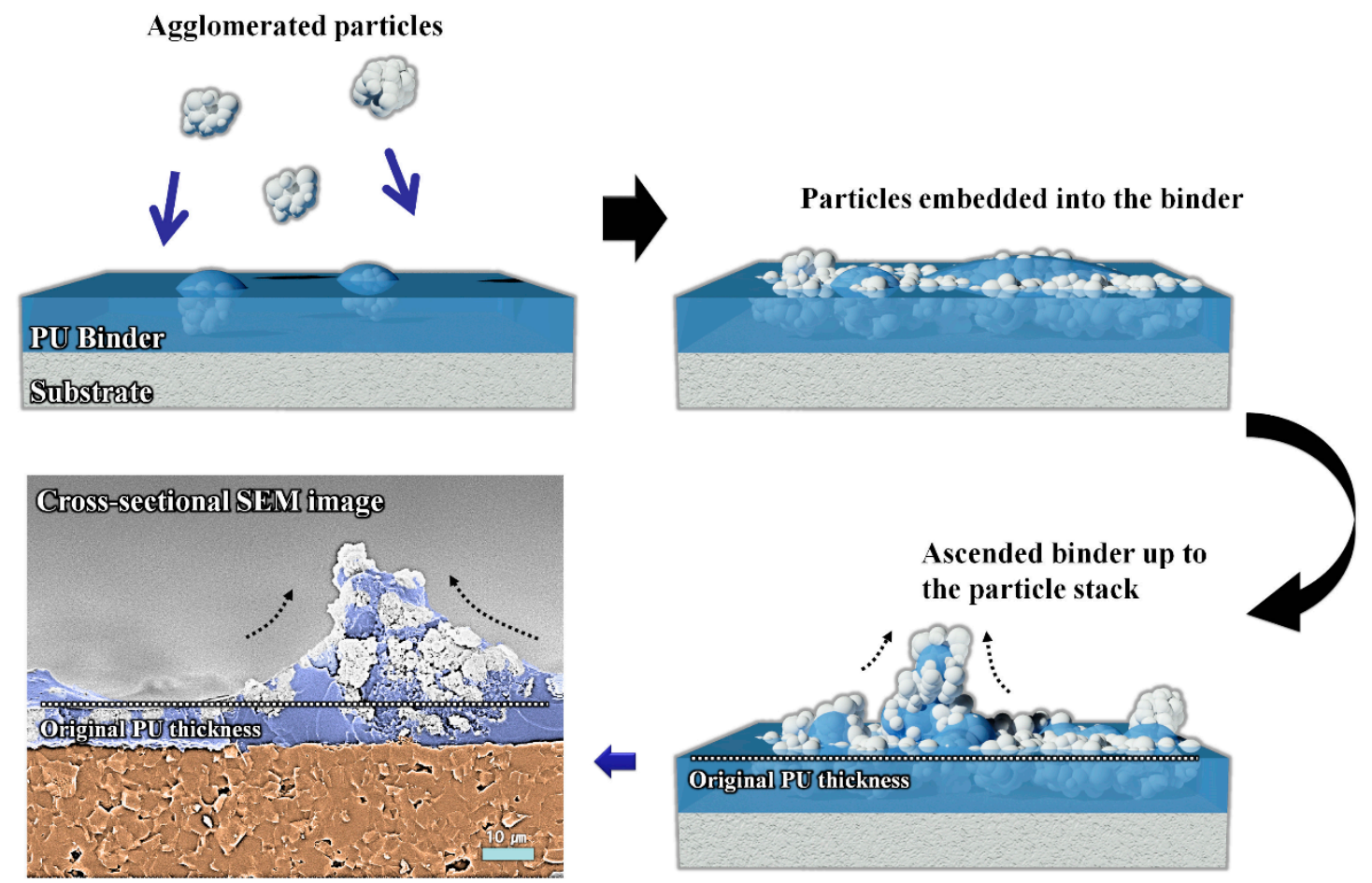

Figure 3. Schematic image of the surface structure assembly mechanism and the fractured SEM image of the sprayed superhydrophobic surface (False color).

One of the obstacles preventing superhydrophobic surfaces from its application in many fields is its poor stability against abrasive wear [42]. It is known that during the friction cycle, the micro-protuberances are easily broken, the surface becomes smoother, and eventually superhydrophobicity will be lost. Polyurethane (PU) based elastomers have a successful history of application on improving mechanical properties of superhydrophobic surfaces, since they can retain the structure even after abrasion. Changhong et al. have fabricated superhydrophobic surfaces on porous $\mathrm{Al}$ template using PU elastomers, they could keep superhydrophobicity even after 10,000 cycles of rubbing at $18 \mathrm{~cm} \cdot \mathrm{s}^{-1}$ with a load of $2945.7 \mathrm{~Pa}$ [43]. As evident from Figure 3, the $\mathrm{SiO}_{2}$ nanoparticles are completely surrounded by PU binder. The presence of binder in the composite structure can resist or partially absorb mechanical stresses applied to it. The durability of the superhydrophobic surface was evaluated through abrasion testing. Milionois et al. and Bayer et al. have extensively reviewed the available superhydrophobic materials and commented on their mechanical integrity. There are various techniques to analyze mechanical durability of a superhydrophobic surface, such as adhesion tape peeling, sand abrasion test and tangential abrasion test (Table 1) [11,44,45]. In this work, 
we performed a tangential mechanical abrasion test to evaluate the durability of coating over several cycles of abrasion.

Table 1. Comparison of abrasion wears resistance with the previous reports on the superhydrophobic surface based on spray coating of composited materials.

\begin{tabular}{cccc}
\hline $\begin{array}{c}\text { Superhydrophobic } \\
\text { Material/Method }\end{array}$ & Total Abrasion Cycles & Load & Reference \\
\hline $\mathrm{MoS}_{2} / \mathrm{PU}$ (spray coating) & Over 100 m rubbing distance & $500 \mathrm{~g}$ & Tang et al. [46] \\
$\mathrm{SiO}_{2} /$ Starch (spray coating) & 17 & $1.1-2.1 \mathrm{kPa}$ & Milionis et al. [47] \\
$\mathrm{SiO}_{2} / \mathrm{Siloxane}$ (spray coating) & 10 & $<10 \mathrm{kPa}$ & Chen et al. [48] \\
$\mathrm{SiO}_{2} / \mathrm{EAC}$ (spray coating) & 10 & $40 \mathrm{kPa}$ & Tenjimbayashi and Shiratori [49] \\
$\mathrm{Grephene}_{\text {PU (spray coating) }}$ & 30 & $15 \mathrm{kPa}$ & Naderizadeh et al. [45] \\
$\mathrm{SiO}_{2} / \mathrm{PU}$ (spray coating) & 100 & $3.138 \mathrm{kPa}$ & Our study \\
\hline
\end{tabular}

For the evaluation, the advancing and receding contact angle was measured before and after the abrasion. The rubbing test was conducted, as shown in the inset of Figure 4, applying $3.138 \mathrm{kPa}$ load on it. In Figure 4, the effect of abrasion on superhydrophobicity was plotted for surfaces with varying powder/binder $\left(R_{-}\right)$ratio. It is primarily understood from the figure that useful results are obtained only for surfaces with $R_{-}$from 0.9 to 1.2. In the proposed range, the advancing contact angle is $158^{\circ}-159^{\circ}$, and the hysteresis is $4^{\circ}-5^{\circ}$ before rubbing. Surprisingly, even after rubbing, the advancing contact angle is between $153^{\circ}$ and $154^{\circ}$, and hysteresis between $7^{\circ}$ and $9^{\circ}$. One of the criteria for superhydrophobic surfaces-hysteresis less than $10^{\circ}$ is well maintained from 0.9 to 1.2 . It is only possible in a range of ensuring durability by compositing the surface structure mentioned above. For $R_{-}$values less than 0.9 and greater than 1.2, there is a big difference between advancing and receding angle before and after abrasion. In surfaces with lower R_ ratios, as clear from Figure 2, the roughness is too low. For R_0.2, there was a sudden fall in advancing angle after abrasion from $147^{\circ}$ to around $125^{\circ}$, which cannot retain superhydrophobicity. After abrasion, the advancing angle of R_0.4 reduced from $155.6^{\circ}$ to $147.2^{\circ}$ with a hysteresis of $4.6^{\circ}$. Even a very small change in protuberance height can offer a very high fall in contact angle. For higher $R_{\text {_ values, }} \mathrm{R}_{\text {_ greater than }} 1.2$ all substrates showed superhydrophobicity before rubbing (advancing angles $\geq 158^{\circ}$, hysteresis $\leq 6^{\circ}$ ). However, it cannot maintain non-wetting after abrasion, and, consequently, the measured advancing angles of $R \_1.3$ and $R \_2.1$ reduced to $141^{\circ}$ and $132^{\circ}$, respectively. Loss of superhydrophobicity is expected due to the poor attachment of $\mathrm{SiO}_{2}$ nanoparticles with the PU binder, since the spray-coated thickness is above the penetration level of binder. Hence, any type of mechanical wear can wash away the surface roughness and make it flatter. A second observation is that irrespective of the R_ratio, abrasion has reduced the contact angle of all substrates. In the given fabrication mechanism, even if the structure is broken, due to the destruction of the binder by abrasion, the $\mathrm{SiO}_{2}$ particles can be exposed on the surface, and the roughness and hydrophobicity can be maintained. Thus, the durability of the surface against mechanical abrasion can be improved to higher levels than the conventional nanostructured superhydrophobic surface. A comparison of the abrasion test with other available literature data are presented in Table 1: The obtained results are promising and comparable with the literature data. 

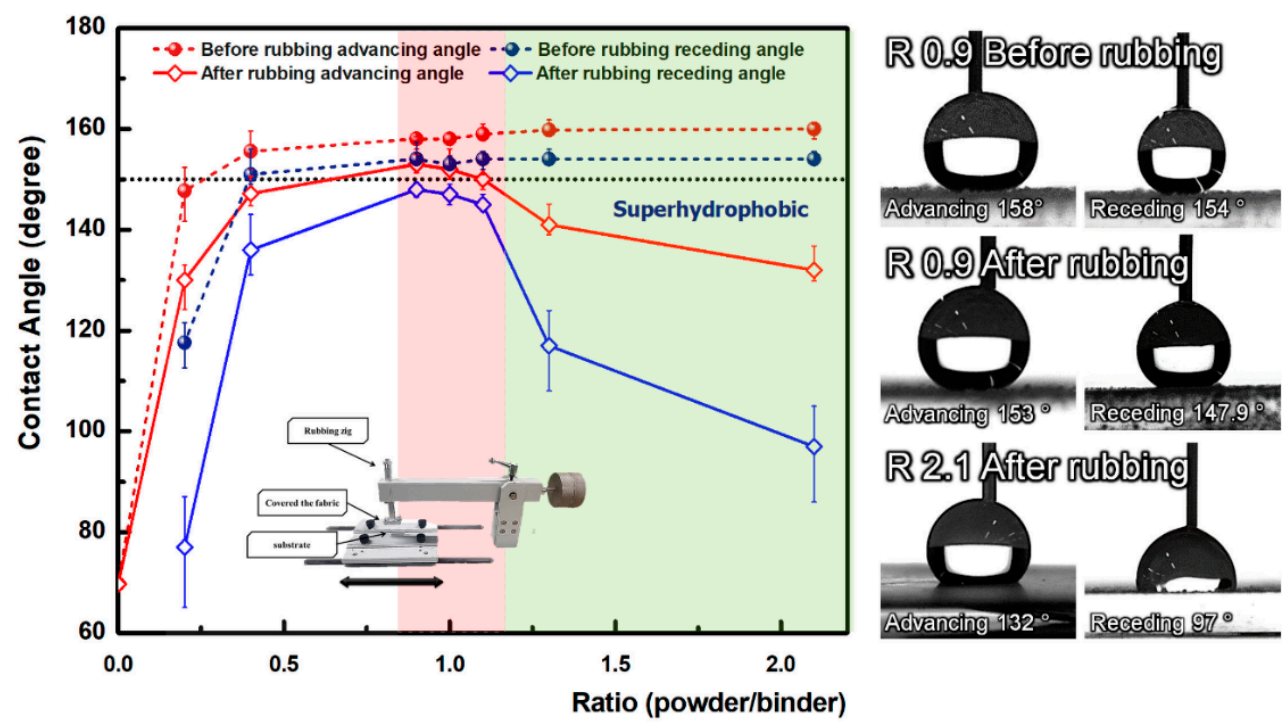

Figure 4. Advancing and receding contact angles with different particle weight ratio surfaces, before and after mechanical abrasion test.

For an in-depth investigation of mechanical abrasion on change in surface structure and performance degradation, we analyzed the degraded surface by SEM and profilometer. Generated roughness and degradation in superhydrophobicity can be evaluated by measuring average surface roughness, $R_{\mathrm{a}}$ and skewness, $R_{\mathrm{sk}}$. The $R_{\mathrm{a}}$, average roughness, is the arithmetic average of the absolute values of the profile heights over the evaluation length. Skewness is a measure of the symmetry of height distribution and provides details about the number of hills and valleys on the surface. $R_{\mathrm{a}}$ and $R_{\mathrm{sk}}$ can be calculated by the following equations [50],

$$
\begin{gathered}
R_{\mathrm{a}}=\frac{1}{N} \sum_{i=1}^{N}\left|Z_{i}-\bar{Z}\right| \\
R_{\mathrm{sk}}=\frac{1}{R_{\mathrm{q}}{ }^{3}} \frac{1}{N} \sum_{i=1}^{N}\left(Z_{i}-\bar{Z}\right)^{3}
\end{gathered}
$$

where $N$ equal to 18,000 , is the total number of measured points for a scan length of $2 \mathrm{~mm}, R_{\mathrm{q}}$ is root-mean-square (RMS) roughness which is calculated by the profilometer software from the measured height data, $\bar{Z}$ is the mean-height distance, and surface height data $Z_{i}$ obtained from scan area. SEM images of Figures $2 a-d$ and $5 c$, d indicate that with an increase in the amount of sprayed articles, the surface roughness also increases. Due to the increased roughness, the number of air pockets also increases, and superhydrophobicity is achieved. However, surface roughness $\left(R_{\mathrm{a}}\right)$ itself is not a suitable parameter to explain the superhydrophobicity-we should depend on other factors, such as skewness $\left(R_{\mathrm{sk}}\right)$, for a complete interpretation. Negative skewness indicates a greater percentage of the profile is above the mean line, and a positive value indicates a greater percentage is below the mean line. When the absolute value of $R_{\mathrm{sk}}$ approaches zero, the shape of the surface tends to be regular and symmetric. For example, if $R_{\mathrm{sk}}$ is a high positive value, it would tend to have a large number of hills, and few valleys on the surface [50,51]. Since the basic strategy behind constructing superhydrophobic surfaces are creating microscale rough structures with long range order and symmetry, skewness can provide more information on this phenomenon. 

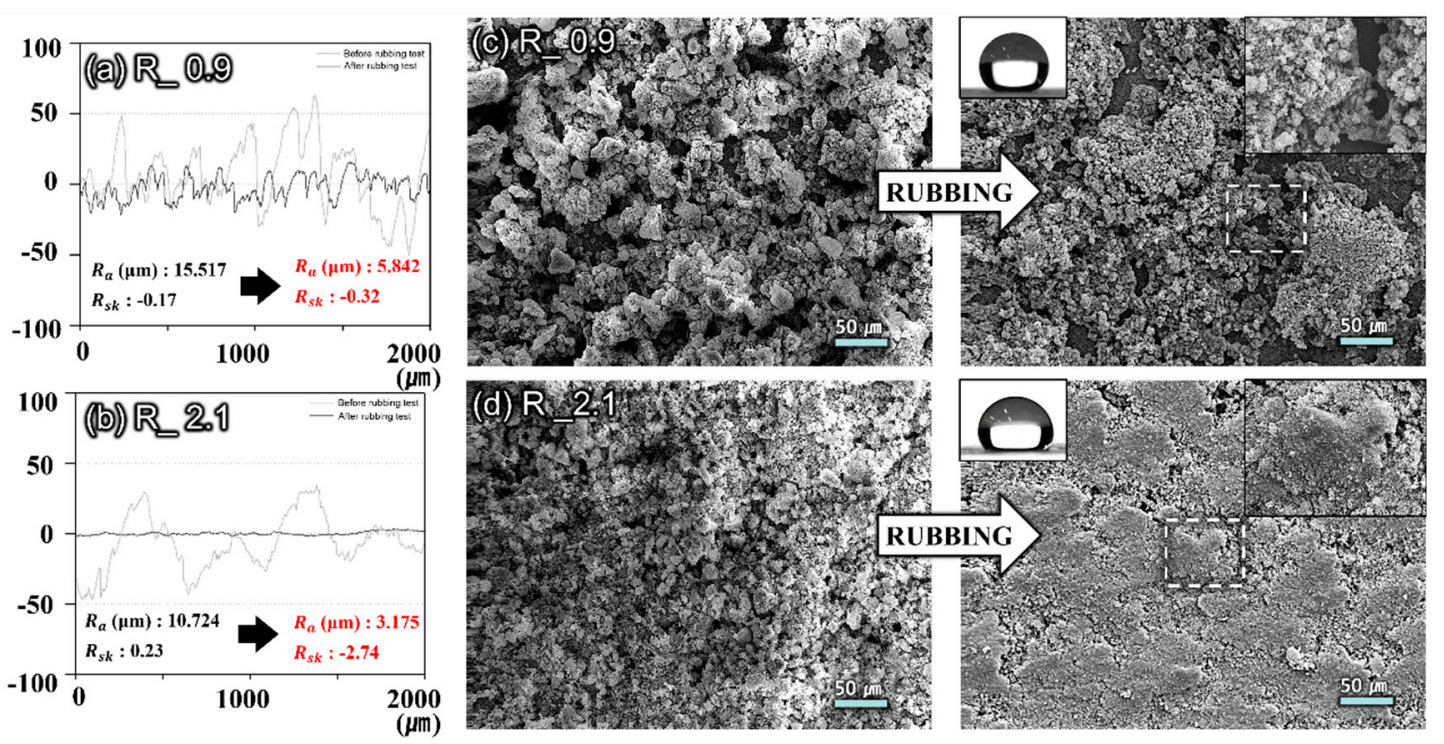

Figure 5. Roughness profiles before and after rubbing the surface with (a) R_0.9 (b) R_2.1 and SEM images before and after rubbing and contact angle images after rubbing the surface with (c) R_0.9 (d) R_2.1.

Figure $5 a, b$ shows the roughness data of the surface of $R \_0.9$ and $R \_2.1$ before and after abrasion test. For R_0.9, even though the roughness has undergone a threefold reduction from 15.517 to $5.842 \mu \mathrm{m}$, due to the abrasion, the comparatively similar skewness tells us that the profile is still symmetric and regular. Since the difference in $R_{\mathrm{sk}}$ before and after abrasion is negligible, the superhydrophobicity could be maintained [52]. These observations are in well agreement with the surface morphology of R_0.9 (Figure 5c). By contrast, $R \_2.1$ shows a large change in $R_{\mathrm{a}}$ and $R_{\mathrm{sk}}$ after rubbing. A remarkable reduction in $R_{\mathrm{a}}$ from 10.7 to $3.17 \mu \mathrm{m}$ is observed, whereas $R_{\mathrm{sk}}$ reached a very low value of -2.74 after prolonged rubbing. The reason for the decreased contact angle can be attributed to the value of skewness. As described earlier, a negative $R_{\text {sk }}$ means that the roughness parameter is tilted up. Since $R_{\mathrm{sk}}$ shows high negative value, it could be predicted that the surface had few numbers of deep valleys and relatively flat top surface. It is consistent with the SEM images of Figure $5 \mathrm{~d}$. In fact, in the analysis by SEM observation, there are no more protuberances observed on the surface of R_2.1 after rubbing (Figure 5d), and a flattened surface is obtained. The flat surface with few deep valleys is not accounted for by the collapse of surface structures as reported previously. This flatness is the result of the removal of particles from the top of the hills and its deposition in the deep valleys. Since $\mathrm{R} \_2.1$ contains a quantity of $\mathrm{SiO}_{2}$ powder greater than its accommodation limit, there can be few layers of particles which are ahead of the penetration limit of PU, are loosely attached. On rubbing, these particles are easily removed from the top and deposited inside the deeper valleys. This process reduces the number of air-pockets, and, hence, suppresses superhydrophobicity, as it depends on the number of air cavities on the top surface. This observation is matching with the SEM image of Figure $5 d$.

To summarize, the binder, as mentioned in the description of the mechanism, penetrated through the particles, mixed, and combined to form a composite material, which could resist stress and support the particles. With this mechanism, we fabricated a robust superhydrophobic surface based on the penetration of polymer and organic solvent.

\section{Conclusions}

This paper discusses the fabrication of superhydrophobic surface by spray coating functionalized $\mathrm{SiO}_{2}$ nanoparticle on PU binder on a different substrate. The robustness of the coating against mechanical abrasions was tested, and its effect on superhydrophobicity is analyzed by contact angle measurement with the support of surface profilometer and SEM analysis. We systematically 
investigated the influence of the weight fractions of surface functionalized $\mathrm{SiO}_{2}$ nanoparticle and $\mathrm{PU}$ binder on the superhydrophobic performance of the surface. The capillary action of the dissolved binder through the agglomerated particle is observed and is responsible for holding the particle tightly and keep it protected against mechanical abrasion. This particular behavior of the binder is first identified in our work. The samples with specific ratio demonstrated a contact angle greater than $150^{\circ}$ after 100 abrasion cycles, and the optimum ratio for maintaining the surface structure against mechanical abrasion is obtained between 0.9 and 1.2. The relatively high abrasion resistance is believed to be due to the influence of the mechanically strong PU binder employed here. In addition, the principle of performance degradation and the collapse of the surface structure were studied through the roughness analysis. Over the optimized particle ratio, interesting surface changes, due to collapse is observed after rubbing. In particular, a flat surface structure was generated by the unsupported and excessive particle lumps. As the structure changed, the superhydrophobic performance was lowered as well. The design and manufacture with the proposed particle-to-binder ratio could increase the mechanical durability of the superhydrophobic surface.

Author Contributions: Conceptualization, D.K. and S.L.; Methodology, D.K. and A.S.; Resources, D.K., A.S. and K.H.Y.; Formal analysis, D.-J.Y.; Investigation, D.K., W.I.P. and J.B.; Data curation, D.-J.Y.; Visualization, K.H.Y. and J.B.; Writing-Original Draft Preparation, D.K.; Writing-Review and Editing, A.S. and Y.L.; Supervision, S.L.; Project Administration, S.L.; Funding Acquisition, S.L.

Funding: This work was supported by the National Research Foundation of Korea (NRF, NRF-2017R1D1A1B03035258) grant funded by the Korea government (MSIT) and the Technology Development Program (S2587969) funded by the Ministry of SMEs and Startups (MSS, Korea).

Conflicts of Interest: The authors declare no conflict of interest.

\section{References}

1. Lee, B.J.; Zhang, Z.; Baek, S.; Kim, S.; Kim, D.; Yong, K. Bio-inspired dewetted surfaces based on SiC/Si interlocked structures for enhanced-underwater stability and regenerative-drag reduction capability. Sci. Rep. 2016, 6, 24653. [CrossRef] [PubMed]

2. Yang, Y.; Li, X.; Zheng, X.; Chen, Z.; Zhou, Q.; Chen, Y. 3D-printed biomimetic super-hydrophobic structure for microdroplet manipulation and oil/water separation. Adv. Mater. 2018, 30, 1704912. [CrossRef] [PubMed]

3. Peng, C.; Chen, Z.; Tiwari, M.K. All-organic superhydrophobic coatings with mechanochemical robustness and liquid impalement resistance. Nat. Mater. 2018, 17, 355-360. [CrossRef] [PubMed]

4. Jankauskaite, V.; Narmontas, P.; Lazauskas, A. Control of polydimethylsiloxane surface hydrophobicity by plasma polymerized hexamethyldisilazane deposition. Coatings 2019, 9, 36.

5. Sakai, M.; Song, J.-H.; Yoshida, N.; Suzuki, S.; Kameshima, Y.; Nakajima, A. Relationship between sliding acceleration of water droplets and dynamic contact angles on hydrophobic surfaces. Surf. Sci. 2006, 600, L204-L208. [CrossRef]

6. Han, M.H.; Park, Y.H.; Hyun, J.W.; Ahn, Y.H. Facile method for fabricating superhydrophobic surface on magnesium. Bull. Korean Chem. Soc. 2010, 31, 1067-1069. [CrossRef]

7. Dai, X.; Sun, N.; Nielsen, S.O.; Stogin, B.B.; Wang, J.; Yang, S.; Wong, T.-S. Hydrophilic directional slippery rough surfaces for water harvesting. Sci. Adv. 2018, 4, eaaq0919. [CrossRef]

8. Karmouch, R.; Ross, G.G. Superhydrophobic wind turbine blade surfaces obtained by a simple deposition of silica nanoparticles embedded in epoxy. Appl. Surf. Sci. 2010, 257, 665-669. [CrossRef]

9. Feng, L.; Che, Y.; Liu, Y.; Qiang, X.; Wang, Y. Fabrication of superhydrophobic aluminium alloy surface with excellent corrosion resistance by a facile and environment-friendly method. Appl. Surf. Sci. 2013, 283, 367-374. [CrossRef]

10. Lee, S.; Kim, W.; Yong, K. Overcoming the water vulnerability of electronic devices: A highly water-resistant $\mathrm{ZnO}$ nanodevice with multifunctionality. Adv. Mater. 2011, 23, 4398-4402. [CrossRef]

11. Bayer, S.I. On the durability and wear resistance of transparent superhydrophobic coatings. Coatings 2017, 7, 12. [CrossRef]

12. Zeng, Y.; Qin, Z.; Hua, Q.; Min, Y.; Xu, Q. Sheet-like superhydrophobic surfaces fabricated on copper as a barrier to corrosion in a simulated marine system. Surf. Coat. Technol. 2019, 362, 62-71. [CrossRef] 
13. Jokinen, V.; Kankuri, E.; Hoshian, S.; Franssila, S.; Ras, R.H.A. Superhydrophobic blood-repellent surfaces. Adv. Mater. 2018, 30, 1705104. [CrossRef] [PubMed]

14. Pan, Q.; Wang, M.; Wang, H. Separating small amount of water and hydrophobic solvents by novel superhydrophobic copper meshes. Appl. Surf. Sci. 2008, 254, 6002-6006. [CrossRef]

15. Teisala, H.; Tuominen, M.; Aromaa, M.; Mäkelä, J.M.; Stepien, M.; Saarinen, J.J.; Toivakka, M.; Kuusipalo, J. Development of superhydrophobic coating on paperboard surface using the liquid flame spray. Surf. Coat. Technol. 2010, 205, 436-445. [CrossRef]

16. Lai, Y.; Gao, X.; Zhuang, H.; Huang, J.; Lin, C.; Jiang, L. Designing superhydrophobic porous nanostructures with tunable water adhesion. Adv. Mater. 2009, 21, 3799-3803. [CrossRef]

17. Lim, H.S.; Han, J.T.; Kwak, D.; Jin, M.; Cho, K. Photoreversibly switchable superhydrophobic surface with erasable and rewritable pattern. J. Am. Chem. Soc. 2006, 128, 14458-14459. [CrossRef] [PubMed]

18. Saleema, N.; Sarkar, D.K.; Gallant, D.; Paynter, R.W.; Chen, X.-G. Chemical nature of superhydrophobic aluminum alloy surfaces produced via a one-step process using fluoroalkyl-silane in a base medium. ACS Appl. Mater. Interfaces 2011, 3, 4775-4781. [CrossRef] [PubMed]

19. Han, J.T.; Xu, X.; Cho, K. Diverse access to artificial superhydrophobic surfaces using block copolymers. Langmuir 2005, 21, 6662-6665. [CrossRef]

20. Xue, C.H.; Jia, S.T.; Chen, H.Z.; Wang, M. Superhydrophobic cotton fabrics prepared by sol-gel coating of $\mathrm{TiO}_{2}$ and surface hydrophobization. Sci. Technol. Adv. Mater. 2008, 9, 35001. [CrossRef]

21. Senesi, G.S.; D'Aloia, E.; Gristina, R.; Favia, P.; d'Agostino, R. Surface characterization of plasma deposited nano-structured fluorocarbon coatings for promoting in vitro cell growth. Surf. Sci. 2007, 601, 1019-1025. [CrossRef]

22. Pan, G.; Xiao, X.; Yu, N.; Ye, Z. Fabrication of superhydrophobic coatings on cotton fabric using ultrasound-assisted in-situ growth method. Prog. Org. Coat. 2018, 125, 463-471. [CrossRef]

23. Rivero, J.P.; Iribarren, A.; Larumbe, S.; Palacio, F.J.; Rodríguez, R. A comparative study of multifunctional coatings based on electrospun fibers with incorporated $\mathrm{ZnO}$ nanoparticles. Coatings 2019, 9, 367. [CrossRef]

24. Verho, T.; Bower, C.; Andrew, P.; Franssila, S.; Ikkala, O.; Ras, R.H.A. Mechanically durable superhydrophobic surfaces. Adv. Mater. 2010, 23, 673-678. [CrossRef] [PubMed]

25. Huovinen, E.; Takkunen, L.; Korpela, T.; Suvanto, M.; Pakkanen, T.T.; Pakkanen, T.A. Mechanically robust superhydrophobic polymer surfaces based on protective micropillars. Langmuir 2014, 30, 1435-1443. [CrossRef] [PubMed]

26. Xiu, Y.; Liu, Y.; Hess, D.W.; Wong, C.P. Mechanically robust superhydrophobicity on hierarchically structured Si surfaces. Nanotechnology 2010, 21, 155705. [CrossRef] [PubMed]

27. Lu, Y.; Sathasivam, S.; Song, J.; Crick, C.R.; Carmalt, C.J.; Parkin, I.P. Robust self-cleaning surfaces that function when exposed to either air or oil. Science 2015, 347, 1132-1135. [CrossRef] [PubMed]

28. Lazauskas, A.; Grigaliūnas, V.; Jucius, D. Recovery behavior of microstructured thiol-ene shape-memory film. Coatings 2019, 9, 267. [CrossRef]

29. Aslanidou, D.; Karapanagiotis, I.; Panayiotou, C. Superhydrophobic, superoleophobic coatings for the protection of silk textiles. Prog. Org. Coat. 2016, 97, 44-52. [CrossRef]

30. Karapanagiotis, I.; Manoudis, P.N.; Savva, A.; Panayiotou, C. Superhydrophobic polymer-particle composite films produced using various particle sizes. Surf. Interface Anal. 2012, 44, 870-875. [CrossRef]

31. Manoudis, P.N.; Karapanagiotis, I.; Tsakalof, A.; Zuburtikudis, I.; Panayiotou, C. Superhydrophobic composite films produced on various substrates. Langmuir 2008, 24, 11225-11232. [CrossRef] [PubMed]

32. Boinovich, L.; Emelyanenko, A. Principles of design of superhydrophobic coatings by deposition from dispersions. Langmuir 2009, 25, 2907-2912. [CrossRef] [PubMed]

33. Rahman, I.A.; Padavettan, V. Synthesis of silica nanoparticles by sol-gel: Size-dependent properties, surface modification, and applications in silica-polymer nanocomposites-A review. J. Nanomater. 2012, $2012,8$. [CrossRef]

34. Sriramulu, D.; Reed, E.L.; Annamalai, M.; Venkatesan, T.V.; Valiyaveettil, S. Synthesis and characterization of superhydrophobic, self-cleaning nir-reflective silica nanoparticles. Sci. Rep. 2016, 6, 35993. [CrossRef] [PubMed]

35. Ulman, A. Formation and structure of self-assembled monolayers. Chem. Rev. 1996, 96, 1533-1554. [CrossRef]

36. Sagiv, J. Organized monolayers by adsorption. 1. Formation and structure of oleophobic mixed monolayers on solid surfaces. J. Am. Chem. Soc. 1980, 102, 92-98. [CrossRef] 
37. Rashvand, M.; Ranjbar, Z.; Rastegar, S. Nano zinc oxide as a UV-stabilizer for aromatic polyurethane coatings. Prog. Org. Coat. 2011, 71, 362-368. [CrossRef]

38. Rosu, D.; Rosu, L.; Cascaval, C.N. IR-change and yellowing of polyurethane as a result of UV irradiation. Polym. Degrad. Stab. 2009, 94, 591-596. [CrossRef]

39. Gaines, G.L., Jr. Surface and interfacial tension of polymer liquids-A review. Polym. Eng. Sci. 1972, 12, 1-11. [CrossRef]

40. Dee, G.T.; Sauer, B.B. The surface tension of polymer liquids. Adv. Phys. 1998, 47, 161-205. [CrossRef]

41. Llaneza, V.; Belzunce, F.J. Study of the effects produced by shot peening on the surface of quenched and tempered steels: Roughness, residual stresses and work hardening. Appl. Surf. Sci. 2015, 356, 475-485. [CrossRef]

42. Roach, P.; Shirtcliffe, N.J.; Newton, M.I. Progess in superhydrophobic surface development. Soft Matter 2008, 4, 224-240. [CrossRef]

43. Su, C.; Xu, Y.; Gong, F.; Wang, F.; Li, C. The abrasion resistance of a superhydrophobic surface comprised of polyurethane elastomer. Soft Matter 2010, 6, 6068-6071. [CrossRef]

44. Milionis, A.; Loth, E.; Bayer, I.S. Recent advances in the mechanical durability of superhydrophobic materials. Adv. Coll. Interface Sci. 2016, 229, 57-79. [CrossRef] [PubMed]

45. Naderizadeh, S.; Athanassiou, A.; Bayer, I.S. Interfacing superhydrophobic silica nanoparticle films with graphene and thermoplastic polyurethane for wear/abrasion resistance. J. Coll. Interface Sci. 2018, 519, 285-295. [CrossRef] [PubMed]

46. Tang, Y.; Yang, J.; Yin, L.; Chen, B.; Tang, H.; Liu, C.; Li, C. Fabrication of superhydrophobic polyurethane/MoS 2 nanocomposite coatings with wear-resistance. Coll. Surf. A Physicochem. Eng. Asp. 2014, 459, 261-266. [CrossRef]

47. Milionis, A.; Ruffilli, R.; Bayer, I.S. Superhydrophobic nanocomposites from biodegradable thermoplastic starch composites (Mater-Biß), hydrophobic nano-silica and lycopodium spores. RSC Adv. 2014, 4, 34395-34404. [CrossRef]

48. Chen, K.; Zhou, S.; Wu, L. Facile fabrication of self-repairing superhydrophobic coatings. Chem. Commun. 2014, 50, 11891-11894. [CrossRef]

49. Tenjimbayashi, M.; Shiratori, S. Highly durable superhydrophobic coatings with gradient density by movable spray method. J. Appl. Phys. 2014, 116, 114310. [CrossRef]

50. Zhang, H.-S.; Endrino, J.L.; Anders, A. Comparative surface and nano-tribological characteristics of nanocomposite diamond-like carbon thin films doped by silver. Appl. Surf. Sci. 2008, 255, 2551-2556. [CrossRef]

51. Horváth, R.; Czifra, Á.; Drégelyi-Kiss, Á. Effect of conventional and non-conventional tool geometries to skewness and kurtosis of surface roughness in case of fine turning of aluminium alloys with diamond tools. Int. J. Adv. Manuf. Technol. 2015, 78, 297-304. [CrossRef]

52. Patel, K.; Doyle, C.S.; Yonekura, D.; James, B.J. Effect of surface roughness parameters on thermally sprayed PEEK coatings. Surf. Coat. Technol. 2010, 204, 3567-3572. [CrossRef]

(C) 2019 by the authors. Licensee MDPI, Basel, Switzerland. This article is an open access article distributed under the terms and conditions of the Creative Commons Attribution (CC BY) license (http://creativecommons.org/licenses/by/4.0/). 